these diseases is a paper which appeared in the Laryngoscope $e^{17}$ from the pen of Dr. B. Douglas of New York. I shall not attempt to do more here than to summarise his results, as my experience of ichthargan in this connexion is a very limited one. For nose and throat work a strength of 4 per cent. will be found most generally useful. In 10 per cent. solutions this remedy produces a disagreeable taste and nasal irritation which lasts from 15 minutes to two hours and causes some congestion of the mucous membrane, with profuse nasal discharge, lacrymation, and a certain amount of sneezing. After much careful experimenting with this new remedy Dr. Douglas found that the strength of solution generally most satisfactory was a 4 per cent. one. This usually caused slight burning and smarting but no congestion. If congestion was present at the time of application the surface soon became pale and contracted. Its action was prompt and lasted for from 15 to 20 minutes. In atrophic rhinitis it acts as a deodorant. It has also anti-inflammatory and stimulant effects and is a powerful modifier of nasal secretion. It is therefore par excellence the remedy for atrophic rhinitis. In hypertrophic cases the best results are got from a 4 or 5 per cent. solution. One of my own cases, that of a girl suffering from atrophic rhinitis, showed marked improvement after the use of a 1 per cent. ichthargan ointment. For syphilitic, tuberculous, and simple chronic laryngitis I have found pigments of a 5 per cent. ichthargan solution extremely useful.

5. Ichthargan in diseases of the eye.-Save of the value of a 0.5 per cent. ointment in cases of marginal blepharitis I cannot speak from personal experience of ichthargan as a remedy of importance in this connexion. Fortunately, however, for my present purpose I am able to quote from the experience of others better qualified to speak on this matter than myself. Thus Guttmann of Breslau has reported ${ }^{18}$ its use in $6 \mathrm{~L}$ cases of eye affections. These include 25 cases of acute catarrhal conjunctivitis, 13 of chronic conjunctivitis, seven resulting from affections of the lacrymal apparatus, ten of trachoma, six of ophthalmia neonatorum, and one of serpiginous ulcer of the cornea. His conclusions may be summarised as follows. In congestive catarrh it proves eficient although it cannot be said to replace the older remedies for such conditions. He recommends that further experiments should be made regarding its use in ophthalmia neonatorum. In affections of the lacrymal apparatus it is a very useful remover of purulent secretion. Its chief action, however, is developed in the dissecting forms of trachoma and it is one of the most useful remedies we at present possess for the medicinal treatment of pannus.

Marczel Falta, ${ }^{19}$ writing of his use of ichthargan in cases of trachoma, says that he has used it in all forms and at all stages of this disease. He found that fresh cases were completely cured by ichthargan in from six to eight weeks. In chronic cases the pannus is reduced very speedily. $\mathrm{He}$ began with a 0.5 per cent. solution and gradually increased the strength to 3 per cent. These solutions are brushed over the affected part and by this means a pannus showed retrogressive metamorphosis ("Rückbildung") in from three to four days, and a case of recent trachoma could be cured in from six to eight weeks. Similar results were obtained by Gortaloff ${ }^{20}$ in cases of trachoma, who therefore considers ichthargan an excellent remedy for the treatment of trachoma and its complications.

6. Its internal employment.-During the course of his investigations Aufrecht took five grains of ichthargan on three successive days and eight grains on the fourth. No loss of appetite was produced, the urice remained clear and free from albumin, while the stools were unaltered in appearance. This preparation may, therefore, safely be given internally. It may be given in solution in the proportion of from half a grain to two grains dissolved in eight ounces of water and of this a teaspoonful may be taken three or four times a day. It would seem useful in promoting the healing of gastric ulcers. It might also be given as an enema in cases of dysenteric and other intestinal lesions. Not having as yet tried ichthargan in the manner suggested I offer these remaris for what they are worth. Doubtless, further experience will convince us of their accuracy.

7. Ichthargan in veterinary practice. -This is, to me, a subject of much interest and I have gone through a vast collection of German literature in the hope of being able to

17 May, 1902.

18 Woshensolrift fïr Therapie und Hygiene des Anges, vol. v., No. 36. 20 Allgemeine Medicinische Central-Zeitung, 1902, No. 5. place before you a review of the work that has been done abroad in this wide field. Time, however, forbids more than a passing reference. I wish particularly to mention the names of Eugen Bass, Eberhardt, and Leibert in this connexion. Eberhardt employed intravenous injections of ichthargan solution in cases of influenza in horses. The strength used for injection was 1 per cent. in distilled water. His results were such that frequently the temperature fell to normal within two days. This has suggested a similar use of ichthargan in cases of septicæmia as it occurs in man. I wish there was time to go more fully into this matter, as it is one of great interest, but I must not detain you longer.

From what I have said it will be evident that the various preparations of ichthyol have a wide sphere of therapentic application. This remark applies especially perhaps to ichthoform and ichthargan which, after the parent remedy itself, are, in my opinion, two of the most valuable antiinflammatory agents at present in our possession. They are certainly trustworthy in their action and therefore valuable additions to our therapeutic stock. They assuredly deserve to be used more extensively by the profession in this country and if these somewhat brief remarks lead to an awakened interest in the ichthyol compounds I shall feel more than rewarded for the trouble I have taken in bringing them before you.

Edinburgh.

\section{A CASE OF METRITIS AND CELLULITIS IN THE PUERPERIUM TREATED WITH ANTISTREPTOCOCCIC SERUM.}

By JOHN W. DUNOAN, M.B., CH.B. ABERD.

THE patient was a primipara, aged 24 years. The labour was normal after the case came uncer my care, except that the membranes were at the beginuing bound to the uterus by slight adbesions that had to be broken before the os commenced to dilate. There was a history of irritation and discharge from the vulva before labour. The woman had been told by her mother and the nurse to bear down strongly and she had done so for a good while before the time when I first saw her, which was about 7 A.M. on Oct. 8th. Delivery took place the same day at 2 P.M. The perineum externally was intact but some abrasions were found in front afterwards. In the evening the fundus uteri was two fingers' breadth below the umbilicus and half a finger's breadth to the right side. The daily temperature and pulse-rate are shown on the accompanying chart. On the 9th the patient seemed to be doirg very well;

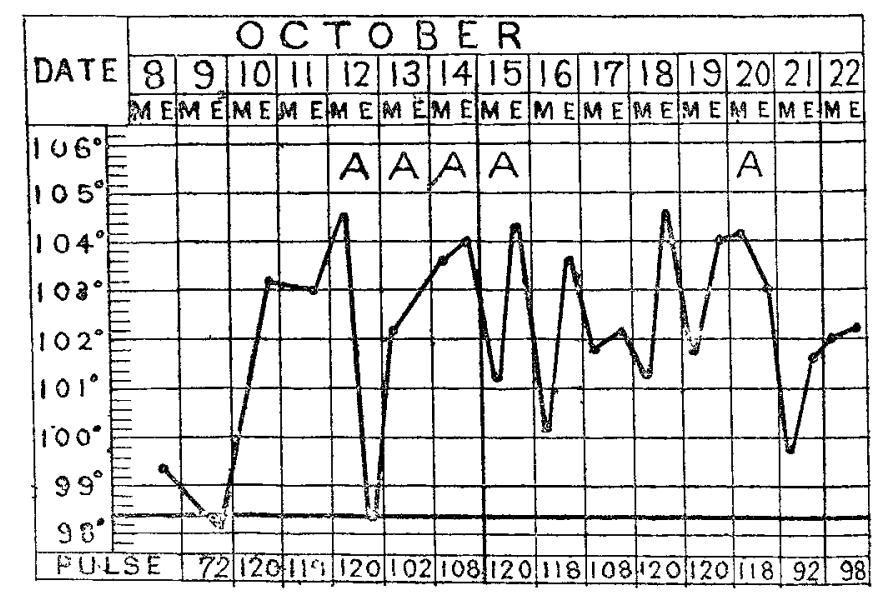

$\Delta$, Ten cubic centimetres of antistreptococcic serum injected.

a fairly normal pulce tracing was taken. The fundus was one finger's breadth above the umbilicus and three fingers' breadth to the right. In the afternoon she complained of pain and the nurse gave her castor oil in the evening. On the 10th there was a motion of the bowels. Headache was complained of and there was pain in the lower part of the abdomen with marked tympanites. The fundus was half finger's breadth above the umbilicus and one finger's breadth to the right. The tongue was brown and furred 
on the dorsum, with whitish edges. The condition was diagnosed as metritis, and turpentine stupes were applied and aperient medicine was given. On the 11th the fundus was three fingers' breadth below the umbilicus and one finger's breadth to the right. Syringing with solution of mercuric chloride was used and iodoform pessaries were ordered; by mistake these were not got and a pellet of mercuric chloride was put in the vagina by the nurse, the consequence being that the patient was thrown into an agony of pain and could not pass urine. At a consultation which was held the consultant approved of the treatment which I was adopting. On the 12th the uterus was five fingers' breadth below the umbilicus. At 2 P.M. when the temperature was $104^{\circ} \mathrm{F}$. and the pulse 120 per minute, ten cubic centimetres of antistreptococcic serum, obtained from Messrs. Burroughs, Wellcome, and Co., were injected, the vaginal outlet was dusted with iodoform, and an iodoform pessary was left in the vagina after the catheter was passed. At 8.45 P.M. the temperature was $98.4^{\circ}$ and the pulse rate 88 . The vaginal abrasions were perfectly clean, showing red granulations where a "diphtheritic" covering had been; the vulva was swollen and slightly everted from irritation by the mercuric chloride. On the 13 th the temperature was $102.2^{\circ}$ as shown in the chart. Tne pain and tympanites were both less but hardness and tenderness were now made out in the left inguinal region and also just above the pubes. The tongue was moist but was still red at the edges with a dirty grey coating on the dorsum. The vulva was now less red and swollen. A tear was discovered in the left side of the cervix and there were many smaller ones around the edge. Ten cubic centimetres of antistreptococcic serum were injected. On the 14th an injection of ten cubic centimetres of antistreptococcic serum in the back was given in the morning and was followed by a fall in the temperature and the pulse-rate. On the 15th an injection of ten cubic centimetres of antistreptococcic serum was given in the afternoon and was followed by a rise of temperature. There was some redness of the back at the site of the injections. The fundus uteri was five and a half fingers' breadth below the umbilicus. On the $16 \mathrm{sh}, 17 \mathrm{th}, 18 \mathrm{th}$, and $19 \mathrm{~h}$ the pyrexia continued. No serum was used. On the 20 th ten cubic centimetres of antistreptococcic serum were injected. On the 21st there was a decided improvement in the patient's condition. On the 22nd there were marked swelling and redness on both arms just above the elbow and bullæ appeared on both legsthree on the right leg and one on the left. The improve ment in the patient's condition nevertheless continued and her temperature became subnormal on the 30th. On the 31 st she was removed in an ambulance vehicle to a more suitable house. On Nov. 6th her temperature rose to $102 \cdot 2^{\circ}$ and the pulse-rate to 112 . The calf of the right leg became red and swollen and an abscess formed in the leg. This abscess and the swelling in the right arm were opened but the swelling in the left arm disappeared without being incised. Convalescence was delayed for about ten weeks from the date of confinement. Some very slight cedema was left in the leg and foot and a slight limp was apparent. Five injections of antistreptococcic serum were given and a fall in the patient's temperature followed three of themnamely, those given on Oct. 12th, 14th, and 20th, while on the contrary a rise followed the two injections given on Oct. 13th and 15th. Only a few indeterminate cocci were found in the vaginal discharge. The onset of metritis was marked by a delay in the involution of the uterus, as shown by the measurements recorded above. The house where the patient was confined was a small fruit shop, the backyard of which abutted on the backyard of a rag-and-bone shop where green, mouldy rabbit skins were to be seen in the window. Next door to the fruit shop was a butcher's shop, and the patient's mother, who was present at the confinement, kept a fish and rabbit shop.

Hockley, Birmingham.

Medical Magistrate.-Mr. T. W. Heywood M.R.O S. Eng., L.R.C.P. Irel., D.P.H., has been appointed a magistrate for the borough of Darwen.

UNIVERSITY OF OXFORD.-Sir John Burdon Sanderson, who ceased to be a member of the Board of Faculty of Medicine on his resignation of the Regins professorship of medicine, has now been made a co-opted member of the board and has been reelected chairman for the current year.

\section{d ettitur}

\section{HOSPITAL PRACTICE, BRITISH AND FOREIGN.}

Enlla antem est alia pro certo noscendi via, nisi quamplurimas et morborum et dissectionum historias, tum aliornm tum propria sollectas habere, et inter se compararo.-MoRGAGNI De Sed. et Carus. Morb., lib. iv., Procemium.

\section{WESTMINSTER HOSPITAL.}

\section{FIVE CASES OF ULCERATIVE COLITIS}

(Under the care of Dr. W. MURRELL)

CASE 1.-A man, aged 21 years, was admibted to Westminster Hospital on May znd, 1903, for diarrbœa and vomiting. He stated that for four months his bowels had been relazed and that for six weeks they had acted very frequently, often 16 or 17 times a day. The motions were fluid and not infrequently mixed with blood. He had had treatment but without benefit. For two days he had suffered from persistent vomiting, with colicky pains in the abdomen, and it was the onset of this symptom which determined his visit to the hospital. His weight had fallen in two months from 9 stones 3 pounds to 6 stones 12 pounds. He was resident in London and had never been abroad; he had had no previous illness and his family history was arimportant. On admission he was found to be thin and wasted and his eyes were sunken and surrounded by dark rims. He looked anæmic but his red blood corpuscles numbered 4,650,000 and the leucocytes 15,400 per cubic millimetre. His mental condition was not impaired and he was always bright and cheerínl. His temperature was elevated and for many months ranged from $100^{\circ}$ to $103^{\circ} \mathrm{F}$. daily. The pulse was 108 and of poor quality. Widal's reaction was not given. The vomiting speedily subsiced and was never a troublesome feature, but the diarrhoea persisted, there being usually about 60 motions a week, most of them hiqnid and offensive. They were passed with very little pain and consisted chiefly of mucus, with from time to time a little blood. The deposit contained strands of mucus in which were many leucocytes but no circular pits denoting the openings of mucous glands. The bacteria of the fæces were almost entirely streptococci but sometimes they were present only in scanty numbers, other organisms being seen of which the majority were large bacilli. The tocgue was clean, red, and slightiy irritable. The appetite from first to last was good and the patient constantly expressed a desire for more food. Thirst was not a prominent symptom. The urine was of specific gravity 1022, faintly acid, and contained neither sugar nor albumin. The abdomen was not cistended and contained no free fluid, there was no enlargement of the liver or spleen, and there was only slight tenderness over the descending colon.

As the patient was in the hospital for eight months it would serve no useful purpose to trace his progress from day to day. The elevation of temperature was constant and the diarrbœa continued persistently and never alternated with periods of constipation. In June an ischio-rectal abscess was detected on the left side and in August there was a similar formation on the opposite side. He was kept strictly in bed and for many months occupied a bright and airy room at the top of the hospital. The windows on account of the foetid odour were kept constantly open, so that the patient had practically open-air treatment. His diet consisted chiefly of milk with a little beef-tea and plasmon arrowroot. Light puddings, chicken panada, and other easily digestible foods were tried from time to time but invariably increased the frequency of the motions. The medicinal treatment consisted in opium and morphine in all forms, including enemata, carbonate of bismuth in doses varying from a drachm to half an ounce every four hours, acetate of lead, perchloride of iron, and other astringents, antiseptics such as $\beta$ naphthol, salol, perchloride of mercury, and various preparations of formic aldehyde, powdered ipecacuanha given dry and with the usual precautions, and many other drugs, none of which seemed to exert the slightest beneficial effect. The patient's general condition was so unsatisfactory that it was considered inadvisable to resort to rectal injections of nitrate 